Revista de la red interuniversitaria de estudios sobre las literaturas rioplatenses contemporáneas en Francia

$8 \mid 2013$

Argentina y Uruguay: lecturas del país vecino en la literatura rioplatense contemporánea (siglos XX y XXI)

\title{
De Arlt a Onetti : camas desde un peso
}

Oscar Brando

\section{(2) OpenEdition}

Journals

Edición electrónica

URL: https://journals.openedition.org/lirico/968

DOI: $10.4000 /$ lirico.968

ISSN: 2262-8339

Editor

Réseau interuniversitaire d'étude des littératures contemporaines du Río de la Plata

Referencia electrónica

Oscar Brando, «De Arlt a Onetti : camas desde un peso», Cuadernos LIRICO [En línea], 8 | 2013,

Publicado el 01 enero 2013, consultado el 21 septiembre 2021. URL: http://journals.openedition.org/ lirico/968 ; DOI: https://doi.org/10.4000/lirico.968

Este documento fue generado automáticamente el 21 septiembre 2021

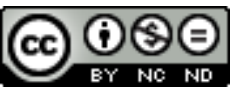

Cuadernos LIRICO está distribuido bajo una Licencia Creative Commons Atribución-NoComercialSinDerivar 4.0 Internacional 


\title{
De Arlt a Onetti : camas desde un peso
}

\author{
Oscar Brando
}

«Soy un hombrecillo inadvertido en la ciudad
ambiciosa, febril y apresurada "
Enrique González Tuñón Camas desde un peso

1 En uno de lo muchos reportajes que mantuvo con María Esther Gilio, ya en Madrid, Juan Carlos Onetti habló, una vez más, de Santa María :

-Para mí Montevideo es una ciudad fantasma.

- ¿Santa María es Montevideo ?

-Santa María es Santa María.

-Una ciudad que usted construye con datos de Montevideo y de Buenos Aires.

-Una ciudad más real que Montevideo. Los recuerdos que tengo de Montevideo me vienen como cosas soñadas. $Y$ a veces son realmente cosas soñadas.

-Está muy presente en usted Montevideo.

-Sí. Creo que Santa María nació para hacer menos dolorosa mi nostalgia de Montevideo.

-Su nostalgia cuando en los cuarenta se fue a vivir a Buenos Aires.

-Claro. Es La vida breve que nace.

-En definitiva que Santa María no es ni Buenos Aires ni Montevideo. Sólo existe en sus libros. Si fuera efectivamente una ciudad que existiera en la realidad, una ciudad sin militares que puedan acusarlo de pornógrafo y meterlo en la cárcel, ¿se iría a vivir allí ?

-Si Santa María fuera una ciudad real yo no tendría otra salida que crear una ciudad melancólica y con mar y viento a la que llamaría « Montevideo ».

-Usted siente más intensamente a Montevideo que a Buenos Aires, a pesar de los sueños que me contó.

-No más intensamente, sino de diferente manera. Montevideo es muchas cosas, pero sobre todo es mi infancia. Y Buenos Aires, la ciudad donde he vivido años muy importantes de mi vida adulta. Pero, bueno, no es mía. Buenos Aires pertenece a Roberto Arlt. Él la ha creado. Esa ciudad es suya. ${ }^{1}$

2 El diálogo tiene numerosos aspectos interesantes: Montevideo, ciudad de la infancia, Santa María como vida vicaria y el imperativo de inventar, siempre, un lugar alternativo. Me interesa la confesión un poco desgarrada de que Buenos Aires no pudo ser suya, a 
pesar de sus numerosos intentos iniciales, porque ya pertenecía a otro inventor : Roberto Arlt.

Debe recordarse que también Arlt, de joven, vivió en dos ciudades: Buenos Aires y Córdoba. De esta no quedó rastro visible en su obra ${ }^{2}$ : sin embargo, todo indica que la primera versión de El juguete rabioso fue escrita allí y hay noticias no suficientemente documentadas de que en Córdoba habría escrito (y tal vez publicado en 1920 o 21) una novela perdida, «El diario de un morfinómano $»^{3}$. Sin dudas la ciudad en la obra de Arlt es Buenos Aires, en la que nació y vivió casi toda su vida. Pero no se desprecie la idea de que esa ciudad literaria se creó con imágenes que el escritor forjó lejos de ella. Esa idea de Onetti de necesitar un territorio vicario para vivir la creación y la ocupación del territorio cuando se consigue aprehenderlo simbólicamente también tuvo su peripecia en Arlt, aunque luego nos quede la idea de un escritor-cronista que va recorriendo palmo a palmo una geografía real para elaborar aguafuertes sobre ella. Las aguafuertes de Arlt fueron un ejercicio creador central, pero no debe confundirse su escritura con la mera reproducción fotográfica del plano urbano que iba recorriendo. De allí que Jaime Rest se animara a escribir :

Su labor periodística se acumula en una serie casi inagotable de piezas en que se va integrando una visión caleidoscópica de la ciudad y sus alrededores : sus habitantes, las formas de vida que estos adoptan, las tareas que realizan. La presencia física y moral de la ciudad está registrada en los artículos de Arlt a través de múltiples aspectos; sobre todo le apasiona registrar cambios, observar transformaciones que pocas veces le resultan estimulantes. Una nota constante de sus observaciones es la nostalgia : nostalgia de casonas y arboledas, nostalgia de jardines, evocaciones de un pasado suficientemente próximo para recordarlo, pero definitivamente perdido para añorarlo. Arlt es, en este sentido, uno de los fundadores de la visión mítica de Buenos Aires: de ese Buenos Aires que ya no está en sus calles, en sus casas, que a veces solo subsiste tímidamente en un rincón oscuro y olvidado. Buenos Aires, en el futuro, habría de convertirse con harta frecuencia en tierra de la memoria, en evocación de un pasado de circunstancias mínimas e intrascendentes que habían dado un tono casi amable, casi íntimo a la vida urbana ${ }^{4}$.

El párrafo sigue y sería aprovechable en toda su extensión, incluso con la trampa de incluir más integrantes a la reflexión : el Borges de la «fundación mítica, el Felisberto Hernández de las «tierras de la memoria ». Pero sería demasiado. Desglosemos un poco la afirmación de Rest. Sin duda si tomáramos en cuenta las casi dos mil aguafuertes que Arlt escribió a lo largo de su vida, la afirmación de Rest se diluiría y no parecería acertada. Incluso si se consideraran los cientos de aguafuertes que abrieron la serie hasta su primera selección en 1933, también resultaría difícil aceptar de lleno la afirmación de Rest. Pero está claro que en el momento de elegir las 69 aguafuertes que formaron el primer libro, Arlt confirmó los términos de Rest : mito, nostalgia, melancolía por lo que se perdió. Las Aguafuertes porteñas de 1933 son las más cercanas a esos sentimientos, las menos circunstanciadas por acontecimientos históricos rotundos, que no faltaron en esos años y a los que Arlt prestó atención : los movimientos políticos de 1930, la ejecución del anarquista Severino di Giovanni, a la que Arlt dedicó una nota memorable, la crisis social durante la década infame. Entre medio, y a medida que se publicaban sus aguafuertes, Arlt había escrito tres novelas : Los siete locos (1929), Los lanzallamas (1931) y El amor brujo (1932), en las que la ciudad rabiosa se revelaba en las geometrías y los gases, en las vibraciones urbanas en sintonía con las almas torturadas y angustiadas de sus personajes. La máquina demoledora, alienante, el mundo impersonal de la gran ciudad se infestaba de la desesperación de los locos arltianos que inventaban estrategias pavorosas para poder 
escapar de él. No son solo los inventos o las fabulaciones de sectas alimentadas por cadenas de prostíbulos, sino sobre todo los sueños febriles, la imaginación desatada que se introduce con brutalidad en la realidad sin poder fijar con ella sus fronteras : digámoslo así, la locura. La ciudad está sofocada, enferma por las bêtes noires arltianas : los tenderos, los pequeños comerciantes que le imprimen su espíritu de « bestial felicidad » y bajo cuya catadura enfática se alza el alma de la ciudad, encanallada, implacable y feroz como ellos. Así lo ve Erdosain en el capítulo « En la caverna » de Los siete locos. En el tranvía, mientras viaja a Ramos Mejía a visitar a los Espila una familia miserable a la que Erdosain alimenta con sueños de inventor o de alquimista: la rosa de cobre, la tintorería de perrosErdosain, la cabeza apoyada contra la ventanilla, sueña. ¿Es un sueño, un recuerdo, el sueño de un recuerdo o viceversa? "Una muchedumbre obscura se movía allí, en el interior de su alma $»^{5}$. En su cabeza, dentro de un cubo exacto, Erdosain instala una inmunda taberna poblada de ladrones y degenerados. Y se imagina (¿o sueña?) contándole a Hipólita, la Coja, cómo allí se formó cuando aún no era ladrón. « Allí iba yo » confiesa Erdosain en su ensoñación, «en busca de más angustia, de la afirmación de saberme perdido» (p. 195-6). Durante páginas Erdosain recordará/soñará viles historias de Ergueta, el farmacéutico, hasta que el tren en el que viaja llega a Ramos Mejía y se baja.

5 La imagen de la ciudad se repite en fórmulas que pasarán de Arlt a Onetti, con estaciones en toda una generación de escritores: Borges, Girondo, Mariani, Scalabrini Ortiz, Raúl González Tuñón. Alguna vez me detuve en una apropiación que se va heredando con fortuna y va de la vida a la obra y de esta otra vez a la vida. Silvio Astier, en El juguete rabioso, desemboca en un lugar que alquila «PIEZAS AMUEBLADAS POR 1 PESO ». En 1932 será Enrique González Tuñón el que escriba Camas desde un peso y un par de años más tarde en la primero extraviada, luego recuperada Tiempo de abrazar, será Onetti el que pondrá su « CASA DE HUÉSPEDES. HABITACIONES DESDE 1 PESO. Sábanas grises, lavatorio de hierro, paredes desconchadas, olor a viejo y humedad $» .^{6}$ Lo peculiar es que años después Onetti devolverá a la vida esa expresión, confesando, en algún reportaje, que salían del semanario Marcha en Montevideo y dormían en esas casas en las que se alquilaban camas por un peso.

6 La primera ciudad de Onetti, si tomamos como inicio «Avenida de Mayo-DiagonalAvenida de Mayo » (1933) y «El posible Baldi » (1936) es la ciudad que convoca aventuras extranjeras. Ya sea por el avance del cosmopolitismo, los afiches cinematográficos, las noticias de la prensa, el habitante urbano busca sustituir su vida rutinaria, anodina, por los « viajes », aventuras y sueños que prometen los personajes de ficción de las carteleras de cine o los extravagantes sujetos que protagonizan noticias de lugares alejados, emblemáticos: Alaska, África, Faruru. Demasiado pegado a Joyce y a Dos Passos en el primer relato, con mejor fortuna en el segundo, Onetti va preparando ese territorio que le permitirá transformar un espacio en otro, traspasar la frontera entre "realidad»y « ficción »7. Esta situación se pondrá a prueba en El pozo y culminará en la maravillosa escena de conversión de Brausen en Díaz Grey, al principio de La vida breve, que supone el ingreso definitivo en Santa María ${ }^{8}$.

7 Siempre vi la relación entre el procedimiento de Onetti en su primer cuento « Avenida de Mayo-Diagonal-Avenida de Mayo » y el episodio 10 de Ulises de Joyce ${ }^{9}$. La diferencia más clara era que, a diferencia del de Joyce, las ensoñaciones del personaje de Onetti lo hacían protagonista de las aventuras que le sugerían las marquesinas de cine o las noticias que leía. Esa conversión de rutina en aventura se repetiría en «El posible Baldi ». Pero un estudio de Rita Gnutzmann sobre « La relación hombre-ciudad en El amor brujo de Roberto 
Arlt » me puso ante otra pista : la de la más probable presencia de John Dos Passos en el cuento de Onetti, influencia ya vista en la novela Tierra de nadie. Gnutzmann observa en la novela de Arlt la proximidad de uno de sus capítulos, "En nombre de nuestra moral», que relata el encuentro de Balder y Zulema en Retiro, con Manhattan Transfer de Dos Passos. La novela, según informa Gutzmann, había sido traducida en 1929 y Arlt la había leído, según responde a un lector que le señala el parecido entre una aguafuerte y la novela. "Manahattan Transfer es una novela que he leído -contesta Arlt a su interlocutor en el aguafuerte "Me ofrecen un perro »- hace precisamente cuatro días. Demás está decir que me ha dejado encantado que mi manera de escribir le guste tanto como la de Dos Passos $» .^{10}$ La escena escrita por Arlt comienza con una descripción nocturna de la Plaza Retiro, en la que se han citado Balder y Zulema. La luna amarilla aparece pintada en el cielo sobre un nimbo verdoso, entre los rascacielos y los carteles publicitarios de neumáticos, galletitas y yerba. El diálogo entre Balder y Zulema, lleno de hipocresías y ocultamientos, se interrumpe en el relato con las distracciones de Balder que observa algún anuncio, los peatones que corren por los andenes de la estación o tres letreros luminosos que se apagan al mismo tiempo. También los deseos sexuales de Balder, que llegan a estremecer su cuerpo, se cargan de las señales urbanas. Vuelve el diálogo que otra vez se intercala con sensaciones visuales, olfativas, auditivas que invaden a Balder. Una vez que Zulema se va deja un paisaje de calle metálica donde Balder piensa largamente en el folletín melodramático en el que está metido : en medio de ensoñaciones cercanas al delirio siguen apareciendo los anuncios, la multitud, los rascacielos, los silbidos del tren. « La ciudad es bella », piensa Balder, o « la vida es magnífica y perfecta », mientras en el intervalo de los neones aparece alguna estrella en el cielo.

El cuento de Onetti es más complejo y también más misterioso. Víctor Suaid, el protagonista, camina por Florida, entre Avenida de Mayo y la Diagonal Norte y, cuando llega a ésta, regresa por la misma calle hasta su punto de partida. En el fondo hay un recuerdo al que él parece dirigirse : una María Eugenia, evocada de blanco, en traje de colegiala $^{11}$, que le produce un golpe de angustia. También hay una imagen de la niñez. Encima de ese oscuro estrato están los pensamientos de Suaid: Alaska, Jack London, Clark Gable y Joan Crawford, las rotativas de un diario que van dejando una noticia oculta debajo de la página siguiente. $Y$ en la capa más exterior la propia realidad que atraviesa Suaid, con la corriente humana, los edificios, la publicidad y los anuncios de noticias que llegan fraccionadas hasta su conciencia. La soledad en la esquina de la Diagonal, su hundimiento en un recuerdo de infancia que le trae un soldadito roto, le permiten recuperar el mundo exterior y lo obligan a desandar las dos cuadras que caminó, ya desiertas de ensueños. Anoche, piensa Suaid, en todo el mundo al mismo tiempo. Aparece entonces un personaje, Owen el inglés, que lo somete a una emoción extrañamente literaria y lo sumerge en un impreciso clima de guerra que será apaciguado por las polícromas de la ciudad. ${ }^{12}$

\section{Caverna y pozo}

Planteemos un rápido paralelo y ciertos cruces entre las escenas de sueño de Erdosain « En la caverna » de Los siete locos y las de los personajes de Onetti, porque si estos habitan las dos ciudades del Plata, en la Buenos Aires de Arlt no falta la sombra o el espejo de un Montevideo maldito. Si nos remontamos hasta el principio de la novela, podremos entender mejor cómo y dónde se producen los sueños de Erdosain. En la descripción, si así 
puede llamarse, de los «Estados de conciencia » se dice que a la atmósfera de sueños y de inquietud por la que circulaba a través de los días como un sonámbulo, Erdosain la bautizaba «la zona de la angustia». Se imaginaba que existía sobre el nivel de las ciudades, a dos metros de altura, y se le presentaba gráficamente bajo la forma de esas regiones de salinas o desiertos. Esta zona de angustia, según Erdosain, era la consecuencia del sufrimiento de los hombres.

Erdosain transita bajo esa zona esperando el acontecimiento extraordinario que dé, hacia arriba, un giro inesperado a su vida o, hacia abajo, actos de humillación que lo hagan sentirse un lacayo. Con una mezcla insólita de formas verbales Arlt crea un relato poderoso que por momentos parece la narración de un sueño (pretérito imperfecto) con chispazos de futuro hipotético que proyecta sus deseos (condicional) y caídas en algo que simula haber sucedido (pretérito perfecto simple) :

Y nuevamente sus pensamientos caían de rebote en una cocina situada en los sótanos de una mansión. En torno a la mesa movíanse dos mucamas, además del chauffeur y un árabe vendedor de ligas y perfumes. En dicha circunstancia él gastaría un saco negro que no alcanzaba a cubrirle el trasero, y corbatita blanca. Súbitamente lo llamaría " el señor ", un hombre que era su doble físico, pero que no se afeitaba los bigotes y usaba lentes. Él no sabía qué es lo que deseaba de él su patrón, mas nunca olvidaría la mirada singular que este le dirigió al salir de la estancia. Y volvía a la cocina a hablar de suciedades con el chauffeur que, ante el regocijo de las mucamas y el silencio del árabe pederasta, contaba cómo había pervertido a la hija de una gran señora, cierta criatura de pocos años. ${ }^{13}$ (p.11-12, la cursiva es mía)

11 Esos delirios, que habitan en la zona de la angustia, acompañan a otros que Erdosain fabula mientras recorre la ciudad:

Me verá una doncella, una niña alta, pálida y concentrada, que por capricho maneje su Rolls-Royce. Paseará tristemente. De pronto me mira y comprende que yo seré su único amor de toda la vida, y esa mirada que era un ultraje para todos los desdichados, se posará en mí, cubiertos sus ojos con lágrimas. El ensueño se desenroscaba sobre esta necedad, mientras lentamente, se deslizaba a la sombra de las altas fachadas y de los verdes plátanos, que en los blancos mosaicos descomponían su sombra en triángulos. (p.14, la cursiva es mía)

Otra vez, en el amasijo de tiempos verbales (ahora el futuro como deseo, con una mancha del presente, se encuadra en el imperfecto del sueño), Erdosain se desliza entre la imaginación y la visión alucinada. La « realidad » sórdida, sin embargo, lo despeñará en el polo opuesto : el prostíbulo.

13 Sería abusivo seguir desgranando los detalles de los sueños de Erdosain : su humillación ante una imagen que lo duplica ; la aparición mágica de una doncella que deviene niña de vestido blanco como el de una colegiala y que lo compra, pero a la que no puede tocar para no manchar su pureza y no perder su poder maravilloso ; su caída en el prostíbulo en el que la angustia por la vida le impide el sexo, etc.

14 Imposible no recordar la escena de la cabaña, y luego su sueño, entre Linacero y Ana María en la novela El pozo. No hay violación y en el ensueño solo está la exhibición del cuerpo desnudo e intocado de la mujer. Una lectura de $E l$ pozo como rebeldía romántica propone la lucha de Eladio Linacero a través de sus sueños y su escritura para derrotar la angustia y la realidad en la que vive. La libertad frente a la realidad y la sumisión a los sentimientos conjugarían la paradoja romántica por excelencia. Según esta versión, el héroe no se entrega, sino que vence el asco, la soledad, el desengaño dejando salir el mundo interior y creándose en la escritura de su vida ${ }^{14}$. A diferencia de la versión del 
pozo romántico, la traductora y comparatista Beatriz Vegh me señaló, en una conversación sobre existencialismo y Nouveau roman, que el pozo de Onetti tenía familiaridad con los agujeros beckettianos. Incluso agregó que la traducción al francés utiliza la palabra puits para titular la obra de Onetti. ${ }^{15}$ Puits es el pozo de donde surge algo (aguas, petróleo, suerte, dicha), y ella entiende más acertado trou, que es agujero, hoyo en el que, como en los agujeros beckettianos, no hay nada.

En su deambular Erdosain encuentra a Ergueta en la esquina de Perú y Avenida de Mayo. El detalle no es menor porque de esa misma esquina parte su caminata Víctor Suaid, el protagonista del primer cuento de Onetti «Avenida de Mayo-Diagonal-Avenida de Mayo ». Ergueta le cuenta a Erdosain que se casó con Hipólita, la Coja. La locura y el milagro rondan la conversación de estos dos extravagantes: Ergueta ha apostado a la Biblia y a la ruleta en Montevideo y argumenta que Jesús le proporcionó el secreto del juego. La conversación alucinada mezcla las santas verdades y la invención con la estafa y el robo, la cocaína y la plata con la revolución social. Pero la locura de Ergueta, que terminará internado, no es tanta como para darle los seiscientos pesos que Erdosain necesita para pagar su robo, y lo despide con el antológico « Rajá, turrito, rajá » (p.22). En el capítulo « La coja » Ergueta ya está internado y en el relato que hace Hipólita vuelve a aparecer Montevideo como lugar del juego. El salto de suerte o de caída se hace de una ciudad a otra: Ergueta gana y pierde y con el dinero se le va finalmente la cordura. Erdosain parte de su casa en la que deja a Hipólita y en el viaje hacia la casa de los Espila en Ramos Mejía, refugio de la invención de la rosa cromada, crea el extenso sueño del delito. Allí reaparecerá Ergueta y al referirse a su matrimonio con Hipólita otra vez el protagonismo lo tendrá Montevideo, donde es posible el divorcio que la ley argentina no admite. En la fábula de Erdosain, que va dirigida a una virtual Hipólita, se detalla el relato que Ergueta le hiciera de su elección de la Coja, su redención por casarse con una prostituta, el desprendimiento de esta de todos sus bienes para entrar « desnuda » a la casa matrimonial. En ese mundo de mentiras, mistificación y crimen Montevideo vuelve a ser ciudad maldita, especie de Sodoma en la que se hacen las apuestas: la ruleta o el matrimonio. Los riesgos de este segundo juego los veremos más adelante.

El sueño de Erdosain «En la caverna », que es el sueño del derrotado, comienza con una encrucijada en la que elige el camino para divagar: "¡Cuántos senderos había en su cerebro! Pero ahora iba hacia el que conducía a la fonda, la fonda enorme que hundía su cubo taciturno como una carnicería hasta los últimos repliegues de su cerebelo » (p.192). Arlt consigue multiplicar el espacio reproduciendo dentro del tren y en el cuerpo del propio Erdosain el cuadrilátero de la fonda :

El cual parecía que ahondaba sus rectas al interior de su pecho, de modo que casi podía admitir que si se mirara en un espejo, el frente de su cuerpo presentara un salón estrecho, ahondando hacia la perspectiva del espejo. Y él caminaba en el interior de sí mismo, sobre un pavimento enfangado de salivazos y aserrín, y cuyo marco perfecto se biselaba hacia lo infinito de las sensaciones adyacentes. (p.193)

Creado dentro de él el espacio en el que incluir la vida vicaria, Erdosain también inventa, con abuso de subjuntivo, el diálogo que justifica la narración y que despeña, como en los personajes de Onetti, la aventura : «Y pensaba que si la Coja hubiera estado a su lado, él le dijera refiriéndose a ese recuerdo $\div$ Aún yo no era ladrón. »(p.193). 


\section{La noche}

18 No solo Erdosain sueña su «caverna » en la que se codea con « las fieras ». Balder, el protagonista de El amor brujo, instala su ensueño « En el País de las Posibilidades ». En el capítulo que lleva ese título leemos :

Balder no duerme. Tampoco piensa. Mientras su cuerpo permanece horizontal en la cama su espíritu a grandes zancos recorre el País de las Posibilidades. [...] Montañas, nieve, casas con techo inclinado, desiertos de nieve, empalizadas blancas, junto a cada verja de roble lo espera Irene, él llega, la abraza, se besan, son esposos. ¿Por qué no ? Comenzar una nueva vida, abandonar a su hijo y a su mujer. ¿Por qué no? El espíritu de Balder recorre a grandes zancos el País de las Posibilidades. Casarse con Irene. Estar junto a ella. Ver siempre su rostro, desayunarse en su compañía, hablar de rascacielos metálicos, con la cabeza apoyada en su hombro y sus manos entre las suyas. Cae nieve afuera. Balder mira la llanura blanca a través de los cristales emplomados, allá lejos hay otros tejados como cubiertos de copos de algodón y magnesia. ${ }^{16}$

En su fantasía Balder viaja a la « copiosa ciudad », en su Hudson, entre la nieve, regresa de noche por un sendero solitario, cenan, el viento aúlla. De pronto golpean la puerta : son su mujer y su hijo. Balder quiere ahuyentar los fantasmas pero de inmediato descubrimos que Balder tiene su ensueño mientras está acostado junto a Elena, su mujer. Entonces piensa en despertarla y comentarle los planes de futuro de la separación, su relación con el hijo, la posibilidad de que su mujer se vuelva a casar si se divorcian ; y al mismo tiempo imagina la vida con Irene. Vuelve la llanura nevada, el Hudson que la atraviesa y los comentarios de su vida gastada con su esposa. "Pero ¿qué es la vida entonces? ¿Una carnicería atroz? ¿Un combate sin piedad?» (p.143) se pregunta Balder, cismando en los malos entendidos entre las personas, en los afectos equivocados. «La nieve cae sobre su espalda y Balder se adormece en el estribo de su Hudson, en medio de la llanura helada del País de las Posibilidades » (p.143) concluye el capítulo.

Este fragmento notable de su tan olvidada novela El amor brujo sintoniza con lo que poco después Onetti haría en sus relatos. El ideal de Balder, « infortunadamente » sólo ocurre en los países donde cae nieve: "Aquí no cae nieve", piensa Balder. "Aquí hay sol, mestizos poéticos y gallegos que acumulan dinero ». (p.139)

21 Un cuento «cordobés » con tuberculosis, que funge como lejano antecedente de «Los adioses » de Onetti, es el magnífico « Ester Primavera » de Arlt. La perversión viene de la mano de la enfermedad: la nieve cae sobre el Sanatorio de Tuberculosos, «allá, a ochocientos kilómetros está Buenos Aires. La noche infinita ocupa un espacio de desolación ${ }^{17}$. El protagonista confiesa que hace setecientos días que piensa, sin pausas, en Ester Primavera. La extraña relación con Ester Primavera había abortado brutalmente cuando el protagonista le había dicho que era casado ; pero a diferencia de Balder, que sí lo estaba y se lo confesaba a Irene, el personaje de "Ester Primavera " inventa su matrimonio y con él, necesariamente, otro personaje. La « prueba » del casamiento es un tópico en Arlt. La disquisición más acuciosa la realiza Ricardo Stepens en "Noche terrible ». Ya Balder jugaba a imaginarse junto a Irene, separado de su esposa, y a ella reanudando su amor con otro para inventar un encuentro civilizado entre los cuatro. Los dostoievskianos Erdosain y Ricardo Stepens alimentan su fracaso con la humillación. El personaje del también muy « ruso » « Ester Primavera » trama una venganza que parece 
proyectarse sobre la mujer pero que es solo un castigo contra sí mismo, la excusa de su obsesión y de la pérdida definitiva de la esperanza.

Ya vimos, en el recorrido de Erdosain hacia la casa de los Espila, el muy onettiano sueño «En la caverna », y en la noche de Balder la necesidad de una revelación. La noche es momento de confesión íntima a la espera de algo terrible que va a suceder. Balder prepara precisamente "La confesión » en la que revelará a Irene que es un hombre casado. Por su parte Ricardo Stepens, protagonista del cuento « Noche terrible », pasa las largas horas previas a su casamiento dudando sobre si hacerlo o no. Stepens baraja interminablemente los argumentos a favor y en contra, rehace desde la medianoche hasta las 7 de la mañana su « historia de amor » repleta de miserias, claudicaciones y renuncias. No falta, aunque con menor intensidad, el tema central de El amor brujo: las dudas sobre la virginidad. El relato se construye como una hipotética prolepsis de qué sucedería si no se presentara a la hora de la boda y también si lo hiciera. La noche ampara las elucubraciones del dilema : una u otra serán las opciones desgraciadas de las que Stepens no podrá escapar.

Más distendidos, Víctor Suaid y el Dr. Baldi caminan por la ciudad cuando cae la noche. Relámpagos de felicidad los iluminan. La emoción no es constante y precisa ser alimentada por los recuerdos y por la imaginación. La blanca y algo fantasmal imagen de María Eugenia en Suaid, la más tangible Nené de Baldi, animan su recorrido afectivo. Suaid, en "Avenida de Mayo...» siente el frío que corre por la calle Florida y lo transforma en Ushuaia, en Alaska, en las orillas del Yukón. Baldi prefiere zonas cálidas : Búfalo Bill, África del Sur, la Legión Extranjera, aunque cierra el cuento «viajando » al Norte a traficar cocaína. Los personajes onettianos necesitan la noche urbana para alimentar sus vidas vicarias. Julio Jason, en Tiempo de abrazar, reflexiona sobre este asunto. Desde la ventana de su oficina, ya concluido el horario de trabajo a las siete de la tarde, se prepara para salir al anochecer tranquilo y caluroso. Inmediatamente se aísla, se vuelve el único habitante del mundo : «La noche se acercaba y él era el primer hombre que la veía. [...] Estaba extraordinariamente alegre, tranquilo, sin pensamientos [...] Era el descubridor de la noche » (p.32). Con esa feliz expectativa cocina una escena en la que el Cantar de los Cantares se instala en la ciudad y la reina de Saba lo acompaña a la «CASA DE HUÉSPEDES. HABITACIONES DESDE 1 PESO.- Sábanas grises, lavatorios de hierro, paredes desconchadas, olor a viejo y humedad... » (p.32). Entre las filas de coches que ve desde la ventana de su oficina, Belkis, la reina de Saba, se convierte en la carnal Cristina. Julio Jason, descubridor de la noche, iniciado en sus misterios y sus ritos, inmóvil desde su ventana, fuma, recuerda. Piensa : "Qué cosa tan extraña el recuerdo, el mecanismo de los recuerdos... Simples remedos de la realidad. Falsos, artificiales y tristes remedos. Una tarea intelectual inferior, amigo Jason. Era necesario agregar elementos extraños al recuerdo mismo para que este alcanzara apariencia de cosa viva » (p.34). Los recuerdos no acercan más que una imagen mutilada de lo que alguna vez entró por los sentidos : tratar de rescatarlos no trae más que dolor. De allí la necesidad de la imaginación, de transformar los recuerdos con experiencias inventadas. Jason conoce la inutilidad de los recuerdos y sabe la decepción que lo espera al enfrentar la realidad. Por eso aprovecha las imágenes de las revistas que cuelgan del quiosco para escaparse un instante antes de que la carnalidad de Cristina derrote su deseo.

24 La culminación de la noche onettiana/celiniana está en El pozo :

Esta es la noche ; quien no pudo sentirla así no la conoce. Todo en la vida es mierda y ahora estamos solos en la noche, atentos, sin comprender. [...] Pero toda la noche 
está, inapresable, tensa, alargando su alma fina y misteriosa en el chorro de la canilla mal cerrada, en la pileta de portland del patio. Esta es la noche. Yo soy un hombre solitario que fuma en un sitio cualquiera de la ciudad; la noche me rodea, se cumple como un rito, gradualmente, y yo nada tengo que ver con ella. Hay momentos, apenas, en que los golpes de mi sangre en las sienes se acompasan con el latido de la noche. He fumado mi cigarrillo, hasta el fin, sin moverme [...] Me hubiera gustado clavar la noche en el papel como una gran mariposa nocturna. Pero, en cambio, fue ella la que me alzó entre sus aguas como el cuerpo lívido de un muerto y me arrastra, inexorable, entre fríos y vagas espumas, noche abajo. Ésta es la noche. Voy a tirarme en la cama, enfriado, muerto de cansancio, buscando dormirme antes de que llegue la mañana, sin fuerzas ya para esperar el cuerpo húmedo de la muchacha en la vieja cabaña de troncos. ${ }^{18}$

Este recurrido fragmento con que se cierra la primera novela publicada por Onetti contiene todos los signos de una poética : lo nocturno aísla, ahonda la soledad, se vuelve ritual interior y espera de un sueño que es al mismo tiempo suspensión de los sentidos y revelación de la imagen primordial para escribir « las confesiones ». El sueño de la cabaña de troncos, creado a partir de una experiencia antigua, sería, si llegara, el generador de una escena que lo salvaría si lograra transformar su pobreza, su mutilación y su dolor. Pero Eladio Linacero no tiene fuerzas para esperarlo, ya hizo lo suyo desnudando su alma en torpes confesiones y, tal vez, deje en las manos de Brausen en La vida breve la misión de la creación mayor.

\section{La cinta de Moebius}

Tenía razón Onetti : «Pero lo que yo escribo no tiene nada que ver con lo que hace Arlt ». ${ }^{19}$ Lugar : Buenos Aires, « allá por 1934 ». Su amigo Kostia lo había convencido de llevarle a Arlt la novela Tiempo de abrazar y Onetti intentaba evitar el papelón. El relato que hace Onetti de la escena (si existió y, en tal caso, si fue así) es muy conocido : a pesar de las prevenciones, llegó con Kostia hasta el diario El Mundo, le alcanzó tímidamente sus páginas, Arlt las hojeó y con una boutade, ante la negativa de Kostia a la pregunta de si él no había publicado nada ese año, concluyó que lo que había leído era la mejor novela escrita en ese año en Buenos Aires. ¿Qué había encontrado Arlt en el texto de Onetti si, como afirmamos, Onetti no se equivocaba? Kostia tenía una respuesta : "Claro que no tiene nada que ver. Arlt es un gran novelista. Pero odia lo que podemos llamar la literatura entre comillas. Y tu librito, por lo menos, está limpio de eso ». La respuesta era buena pero insuficiente. Había otras virtudes que, ya en ciernes en la novela de Onetti, podían interesar a Arlt.

Digamos que en el sentido más intenso Kostia daba en el blanco. Onetti, como Arlt, apostaba a la autenticidad, a una manera de antiliteratura. De allí la admiración de Onetti por los escritores antiintelectuales: Céline, Faulkner, Hemingway, el propio Arlt. La postura onettiana apuntaba ( $i$ diferencia de la de Arlt ?) al despojamiento, y esto se habría de comprobar una vez conocidas las cartas del joven escritor al crítico de arte argentino Julio Payró en la década del 30, en las que la elección recaía sobre las formas depuradas de Cézanne y las imágenes y colores de Gauguin ${ }^{20}$. En un artículo de 1975, «Felisberto, el naif » todavía Onetti seguía admirando al Felisberto liberado de « lo que llamamos literatura, estilo, técnica » y rescatando el «alma desnuda » que algunas de sus obras exhibían. ${ }^{21}$ En El pozo Onetti va a encontrar los nudos principales de la poética que le permitirá desarrollar su obra. He aquí un aspecto que la crítica ha puesto de relieve : la 
pureza inicial, esa austeridad extrema que mostró en El pozo, y que podría considerarse una ganancia frente a la aún indecisa Tiempo de abrazar, no se repetiría con la misma intensidad en sus relatos posteriores. A favor de la coherencia puede argumentarse que sostuvo algunos temas, mantuvo la idea de rescatar el alma de las cosas, siguió indagando la realidad de la ficción, insistió en que lo fundamental jamás puede ser dicho, apostó a que el sentido siempre está en un lado que nunca queda suficientemente iluminado. En la carta a Payró del 22 de diciembre de 1941 escribe al final : «SIEMPRE HAY ALGO que no se dice ${ }^{22}{ }^{22}$

El de la ciudad arltiana es un mapa del dolor humano en el que la angustia se representa en formas geométricas impresionantes y en imágenes opresivas metaforizadas por la mecánica técnica de la industrialización (gases o planchas de acero). Sin duda Arlt le debe bastante al expresionismo, ese intercambio entre lo externo y lo interno, el comentario moral del poder mutilante del espacio urbano, que no es otra cosa que la manifestación de las ambiciones y las frustraciones de los locos, los inventores, los rufianes y las fieras que allí viven (también de los aparentemente pacíficos integrantes de la pequeño burguesía, tenderos y comerciantes, que, liberados de su represión, se convierten en seres ambiciosos e inmorales). Dice Maryse Renaud ${ }^{23}$ que en Arlt tenemos una doble sensación : el vértigo, la velocidad con que se despeñan los acontecimientos y al mismo tiempo la repetición y la monotonía que impide a los acontecimientos avanzar hacia ningún lado. Rose Corral ${ }^{24}$, por su parte, al analizar las asimilaciones periodísticas y folletinescas de las novelas de Arlt, también señala que sobre todo el cronista/comentador se empeña por infundir al relato una apariencia de acción y movimiento, la expectativa de un salto al vacío, que contrasta notablemente con el clima estático y obsesivo de la angustia, de los « estados de conciencia » del protagonista, de la espera de que el milagro, el golpe de suerte o de desgracia se produzcan.

En el caso de Onetti parecen ser las interrogantes sobre la esencia de la ficción, los problemas de representación, la prescindencia aparente de un referente exterior los motivos fundamentales que lo distinguen de los antecedentes que lo influyeron: el existencialismo rioplatense de Arlt, el existencialismo francés, la narrativa de Céline o de Faulkner. Según Juan José Saer ${ }^{25}$ el esquema arquitectónico que se hizo a partir de la presencia del existencialismo y de la lectura de Faulkner, reconocida por Onetti, tuvo sus límites. Saer no duda en filiar a Onetti tanto al existencialismo francés, que apareció en los años en que Onetti comenzaba a escribir, como al existencialismo rioplatense anticipado por Roberto Arlt. Admite que del existencialismo Onetti tomó un repertorio temático que incluyó angustia, soledad, incomunicación, héroes que acometían acciones desesperadas, situaciones límites, fracaso. Pero agrega que la preocupación por la realidad de la ficción, la aguda percepción de los problemas de representación en los relatos de ficción lo separaron tanto del existencialismo como de la narrativa de Arlt, que no se plantearon como central esa pregunta. En relación con Faulkner, Saer advierte que Onetti pudo aprender de él la necesidad de autonomía de mundos, las variaciones técnicas de los relatos, la versatilidad en la formalización. Pero tampoco Faulkner colocó en un lugar central el problema de la representación, sino que buscó los recursos formales que le permitieran aproximarse de mejor manera a una realidad compleja. Los personajes de Onetti parecen desconformes con el lugar en el que el creador los puso y decididos a inventar un mundo paralelo que los recompense de aquellas miserias.

Volviendo a la escena de 1934, en una zona más epitelial pudo haber aspectos que el ojo sagaz de Arlt fue capaz de otear en el Onetti primitivo de Tiempo de abrazar, y que 
convergían con algunas de sus preferencias. Por un lado la manera todavía tumultuosa de Tiempo de abrazar pudo conquistar enseguida a Arlt, pero es posible suponer que, a pesar de la rápida lectura, haya conseguido advertir los asuntos que Onetti le había robado : la historia de amor un poco folletinesca, que remitía a la muy cercana El amor brujo, la influencia de magazines que seguramente compartían, la mezcla de géneros que podía poner en contigüidad un debate sobre arte con la reproducción de tipos populares. Por supuesto estaba el ámbito urbano como degradación, el sentimiento de exilio de los personajes, las muchachas colegialas frente a las mujeres ya consumidas, el mundo adulto como adversario de la juventud y la pureza. Exagerando la capacidad perceptiva, Arlt pudo encontrar expresiones como "puerca vida » que él había pensado utilizar como título para su novela El juguete rabioso y hasta las « camas desde un peso » que aparecen en Tiempo de abrazar y en las que había dormido Silvio Astier, el protagonista de su primera novela. Suponiendo que Arlt hubiese leído el cuento de Onetti «Avenida de MayoDiagonal-Avenida de Mayo » publicado en La Prensa de Buenos Aires el 1 de enero de 1933, y agregando un cierto poder anticipatorio, habría advertido en el escritor oriental el procedimiento de la ensoñación como escape o vida paralela y, a lo lejos, un lugar que ya no podría ser ni Buenos Aires ni Montevideo.

\section{NOTAS}

1. M. E. Gilio, Estás acá para creerme. Mis entrevistas con Onetti, Mont, Cal y Canto, 2009, p. 73.

2. El cuento "Ester Primavera " -publicado el 9 de setiembre de 1928 en el diario La Nacióntranscurre en un hospital para tuberculosos en la sierra, aunque la historia que el enfermo recuerda suceda en Buenos Aires ; pudo tener como sostén referencial la experiencia de Roberto, recién casado, acompañando a su esposa Carmen en sus internaciones en sanatorios de Córdoba a causa de su tuberculosis.

3. R. Larra, Roberto Arlt, el torturado. Una apasionada biografía, Buenos Aires, Ameghino, $1998,7^{\mathrm{a}}$ ed., p. 67 (1ª edición 1950).

4. J. Rest, «Roberto Arlt y el descubrimiento de la ciudad» en El cuarto en el recoveco, Buenos Aires, Cedal, 1993, p. 63.

5. R. Arlt, Los siete locos. Los lanzallamas, Edición crítica, Mario Goloboff Coordinador, Paris, Archivos-Sudamericana, 2000, p. 192.

6. J. C. Onetti, Tiempo de abrazar, Montevideo, Arca, 1994, p. 32.

7. En el cuento «El álbum », ya creada Santa María, Onetti dará vuelta el procedimiento de Baldi. Jorge Malabia, que ha escuchado las historias que le contó la forastera como aventuras fantásticas, se desencanta cuando descubre, en las fotos del álbum olvidado en el hotel, que nada había sido inventado, que todo había acontecido realmente.

8. El desplazamiento o la necesidad de una zona de ficción que cambie las marquesinas urbanas por un escenario de provincia ya se produce en « Un sueño realizado », cuento de 1941. Juan José Saer y Gabriel Saad conversan sobre la literatura urbana en espacios ficcionales no urbanos y la influencia de Faulkner en este procedimiento : «Entrevista a Juan José Saer » en Faulkner desde el otro sur, coord. B. Vegh, Montevideo, Cal y Canto, 2000, p. 54-61.

9. Otra relación, surgida en una conversación con la profesora Beatriz Vegh, es la de Onetti con la cultura, los géneros y en particular las revistas populares -su mención a la revista Titbits que 
hace en un reportaje realizado por Ruffinelli (Palabras en orden, México, Universidad Veracruzana, 1985, p. 121-122)- y el viejo número de Titbits que lee Leopoldo Bloom en el retrete, al final del cuarto episodio de Ulises.

10. R. Gnutzmann, «La relación hombre-ciudad en El amor brujo de Roberto Arlt », en Roberto Arlt, una modernidad argentina, (José Morales Saravia y Barbara Schuchard eds.) Madrid, Iberoamericana-Vervuert, 2001.

11. Como Irene, de El amor brujo, la primera vez que la ve Balder o la doncella imaginada por Erdosain en «El terror en la calle » de Los siete locos; años después, el propio Onetti imaginará a Ceci de blanco en El pozo o a Gertrudis fotografiada de liceal en La vida breve.

12. J. C. Onetti, "Avenida de Mayo-Diagonal Norte-Avenida de Mayo» en Cuentos completos, Madrid, Alfaguara, 1994, p. 27-33.

13. R. Arlt, Los siete locos. Los lanzallamas, op.cit.

14. M. Steenmeijer, «La otra cara de la derrota : rebeldía romántica en El pozo de Juan Carlos Onetti ", en J.C. Onetti Novelas cortas, D. Balderston coord., Córdoba, Alción-Colección Archivos, 2009, p. 503-510.

15. Por ejemplo J.C. Onetti, Le puits, Trad. L. Jolicœur, Paris, Christian Bourgois, 1985, 103 p. Réédition : Paris, U.G.E., 1994, 189 p.

16. El texto es el original en español. La referencia es de la edición francesa que tengo a mano : $R$. Arlt, La danse du feu, traduit par Lucien Mercier, Toulouse, Éditions Ombres, 1997, p. 135-136.

17. R. Arlt, « Ester Primavera », en Cuentos completos, Buenos Aires, Losada, 2008, p. 82.

18. J. C. Onetti, Obras completas I, Novelas I (1939-1954), Ed. de Hortensia Campanella, Barcelona, Galaxia Gutenberg-Círculo de Lectores, 2006, p. 30-31.

19. J.C. Onetti «Prólogo a la edición italiana de Los siete locos, de Roberto Arlt » (1971) en Obras completas III. Cuentos, artículos y miscelánea, Ed. de Hortensia Campanella, Barcelona, Galaxia Gutenberg-Círculo de lectores, 2009, p. 848.

20. Sobre la admiración y la relación que Onetti tuvo por el pintor uruguayo Joaquín Torres García luego de su retorno a Montevideo en 1934, de los que ya había indicios en reportajes y notas, las cartas son también muy elocuentes. J. C. Onetti, Cartas de un joven escritor, edición crítica, estudio preliminar y notas de Hugo Verani, Montevideo, Trilce, 2009.

21. J. C. Onetti, Obras Completas III, op. cit. p. 532-535.

22. J. C. Onetti, Cartas de un joven escritor, op. cit.

23. M. Renaud, "Los siete locos y Los lanzallamas : audacia y candor del expresionismo », en R. Arlt Los siete locos. Los lanzallamas, op. cit. Ver también Janete Elenice Jorge « A cidade arltiana: dialogos com o expresionismo alemao ", en Núcleo Onetti, www.onetti.cce.ufsc.br/ . En el mismo espacio y de la misma autora puede leerse « El Buenos Aires literario : Roberto Arlt y Juan Carlos Onetti ».

24. R. Corral, « Ficción y crónica en Los siete locos y Los lanzallamas », en R. Arlt, Los siete locos. Los lanzallamas, op. cit.

25. J. J. Saer, «El soñador discreto », « Onetti : coloquio internacional », « Sobre Onetti y La vida breve » y « Onetti y la novela breve », en Trabajos, Buenos Aires, Seix Barral, 2005.

\section{RESÚMENES}

La imagen de la ciudad se repite en fórmulas que pasan de Arlt a Onetti, con estaciones en toda una generación de escritores: Jorge Luis Borges, Oliverio Girondo, Roberto Mariani, Raúl 
Scalabrini Ortiz, Raúl González Tuñón. Una escena se va heredando con fortuna y pendula de la vida a la obra y de esta otra vez a la vida. Silvio Astier, en El juguete rabioso (1926), desemboca en un lugar que alquila PIEZAS AMUEBLADAS POR UN PESO. En 1932 será Enrique González Tuñón el que escriba Camas desde un peso, y un par de años más tarde, en Tiempo de abrazar (¿1934?), será Onetti el que imaginará a la reina de Saba entrando a la "CASA DE HUÉSPEDES. HABITACIONES DESDE 1 PESO. Sábanas grises, lavatorio de hierro, paredes desconchadas, olor a viejo y humedad".

Se salta de la Buenos Aires de Arlt y del primer Onetti a la ciudad de Montevideo de El pozo y a la Santa María de La vida breve. Entre el caos y el orden de lo urbano, la ciudad imaginaria funciona como la cinta de Moebius : no hay afuera ni adentro. Mientras los personajes dan lugar a la conocida plancha arltiana de la angustia, la caverna del sueño de Erdosain en Los siete locos y las geografías nevadas en El amor brujo o en Onetti, las « camas desde un peso » tienden entre las dos orillas (¿realidad/ficción ?) un continuo indiscernible.

L'image de la ville se répète dans certaines formules qui passent d'Arlt à Onetti, avec des coupures générationnelles : Jorge Luis Borges, Oliverio Girondo, Roberto Mariani, Raúl Scalabrini Ortiz, Raúl González Tunón. Une scène apparaît et, de manière successive dans la littérature de ces auteurs, oscille entre la vie et la fiction. Silvio Astier, dans El juguete rabioso (1926), arrive à un endroit où des «chambres meublées pour un peso " sont louées. En 1932, Enrique González Tuñón écrira Camas desde un peso, et deux ans plus tard, dans le roman Tiempo de abrazar (1934?), Onetti évoquera la reine de Saba entrant dans une « MAISON D'HÔTES. CHAMBRES À PARTIR DE 1 PESO. Draps gris, lavabo en fer, murs décrépis, odeur de moisi ».

On passe de la Buenos Aires d'Arlt et les premiers récits d'Onetti à la Montevideo de Le puits et à la Santa María de La vida breve. Entre le chaos et l'ordre urbains, la ville imaginaire serait comme le ruban de Möbius où le dedans et le dehors n'existent pas. Tandis que les personnages donnent lieu à la fameuse plaque arltienne de l'angoisse, la grotte obscure des rêves chez Erdosain dans Los siete locos et les géographies enneigées dans El amor brujo ou dans les récits d'Onetti, les « lits à partir d'un peso » créent des liens indissolubles (réalité/fiction?) entre les deux rives.

\section{ÍNDICE}

Keywords: Arlt, city, night, Onetti, dreams, pits

Mots-clés: Arlt, Onetti, ville, nuit, rêves, puits

Palabras claves: Arlt, Onetti, ciudad, noche, sueños, pozos

\section{AUTOR}

\section{OSCAR BRANDO}

Université Charles-- Gaulle Lille 3 